(Aus der Dermatologischen Universitätsklinik Breslau [Direktor: Geh. Rat Prof. Dr. Jadassohn].)

\title{
Wirkung des Serums von Sarkoid-Boeck- und Lupus-pernio-Kranken auf Tuberkulin.
}

\author{
Von \\ Dr. med. Hans Martenstein, \\ Assistènzarzt der Klinik.
}

(Eingegangen am 1\%. August 1921.)

Die Klärung der Ätiologie der beiden nahe verwandten Krankheitsformen: Boecksches Sarkoid und Lupus pernio ist immer noch der Gegenstand lebhafter wissenschaftlicher Auseinandersetzungen; besonders in der neuesten Zeit ist eine ganze Reihe von Arbeiten erschienen, die sich mit dieser Trage befassen. Es erübrigt sich auf die Literatur einzugehen, da diese in den älteren Abhandlungen von $\mathrm{Jadassoh}^{1}$ ), Zieler ${ }^{2}$ ), Lewandows $\mathrm{ky}^{3}$ ) und neuerdings in den Arbeiten von $\mathrm{Kyrle}^{4}$ ), Altmann ${ }^{5}$ ) and $\mathrm{Volk}^{6}$ ) eingehend berücksichtigt ist. Hervorgehoben sei nur noch einmal, daß die einen (Zieler, Kreibich, Kühlmann, Hilgers, Bittorf und Kuznitzky und Volk) das Sarkoid Boeck und den Lupus pernio als chronisches infektiöses Granulom angesehen wissen wollen, dessen Zugehörigkeit noch nicht klar ist; sie lehnen aber mehr oder weniger bestimmt die tuberkulöse Natur ab. Andere (Pa utrier) halten speziell das Sarkoid für ein ,Syndrome“ mit verschiedener Ätiologie (Tuberkulose und Syphilis). Noch andere (Jadassohn, Darier, Kyrle u. a.) neigen auf Grund von klinischen und pathologisch-anatomischen Beobachtungen dazu, die beiden Krankheitsformen zur Tuberkulose zu rechnen. Lewandowsky hält einen Teil der als Sarkoid Boeck und Lupus pernio diagnostizierten Fälle für eine Form der Tuberkulose, den anderen Teil aber für eine Krankheit, die klinisch wohl gleiche oder sehr ähnliche Bilder erzeugt, ätiologisoh aber nichts mit Tuberkulose zu tun hat. Die Versuche, durch Tuberkelbacillennachweis und Tierexperiment die tuberkulöse Ätiologie sicherzustellen, führton bei einer großen Reihe von Untersuchern (siehe Zieler, S. 365 und 376) zu keinem positiven Ergebnis. Die wenigen Veröffentlichungen, die über positive Tierexperimente berichten (K y rle, Morawetz u. a.),

1) Jadassohn, Arch. f. Dermatol. u. Syphilis, Orig. 119. 1914.

2) Zieler, Hauttuberkulose und Tuberkulide. 1914, S. 358.

3) Lewandowsky, Tuberkulose der Haut. 1916.

4) Kyrle, Arch. f. Dermatol. u. Syphilis, Orig. 131, 33.1921.

$\left.{ }^{5}\right)$ Altmann, Arch. f. Dermatol. u. Syphilis, Orig. 135, 1. 1921.

6) Volk, Arch. f. Dermatol. u. Syphilis, Orig. 133, I. 1921. 
sind nicht als beweisend anerkannt worden. Kyrle teilt in seiner neuesten Publikation mit, $\mathrm{da} b \mathrm{ihm}$ der Nachweis säurefester Bacillen gelungen ist, und zwar im ganz frischen Stadium des Boeckschen Sarkoids, das klinisch noch nicht den gewohnten Bildern entspricht. Der Bacillenbefund wurde negativ in den Efflorescenzen, die sich klinisch zum typischen Sarkoid entwickelt hatten, war aber noch positiv, als sich bistologisch bereits deutliche Epithelioidstruktur zeigte. In einer ganz kürzlich erschienenen Arbeit berichtet auch $\mathrm{G}_{\mathrm{an}} \mathrm{s}^{\mathrm{I}}$ ), daß $\mathrm{ihm}$ der Nachweis von Tuberkelbacillen bei einem Fall von sicherem Lupus pernio aus Gewebsstiucken im Tierversuch gelungen ist. Die Versuche, die Tuberkulinreaktionen zur Entscheidung der Frage heranzuziehen, haben die Autoren zu ganz versehiedenen Ansehavungen geführt. Sowohl die eutanen wie die intracutanen Reaktionen, ja auch die subcutanen Injektionen, haben in einer sehr großen Anzahl von Fällen negative Resultate ergeben. Daraus hat z. B. Zieler auf die Nichtzugehörigkeit zur Tuberkulose geschlossen; Jadassohn hat betont, daß die fehlende oder sehr geringe Tuberkulinempfindlichkeit in so zahlreichen Fällen (im Gegensatz zu den Resultaten bei nicht aktiv tuberkulösen, beliebig ausgewählten Menschen) eber im Sinne einer spezifischen Anergie zu sprechen scheint $\left.{ }^{2}\right)^{3}{ }^{4}$ ). Eine Zusammenstellung, die Margarete Loew y aus der Literatur und aus dem Material der hiesigen Klinik vorgenommen hat (Inaug.-Diss. 1921), hat nicht bloß auf breiter Basis die auffallend häufig geringe oder fehlende Tuberkulinempfindlichkeit, sondern auch noch das interessiante Resultat ergeben, daß diejenigen Sarkoid- und Perniopatienten, die anderweitige augenscheinlich tuberkulöse Erkrankungen aufwiesen, in kaum höherem Maße tuberkulin-allergisch waren als die mit diesen Leiden behafteten, sonst nicht nachweisbar Tuberkulösen. In neuester Zeit hat Alt man $n$ in dem ersten seiner beiden Fälle mit der Imptung nach Pirquet positive Resultate nach 48 Stunden erzielt, und zwar waren die Reaktionen im Gesunden deutlich positiv, an der Grenze des gesunden und erkrankten Gewebes sehr schwach positiv, im erkrankten Gewebe selbst negativ.

Bei dem allgemein-pathologischen Interesse, das diese Frage bietet, schien es mir notwendig, von möglichst verschiedenen Versuchsmethoden Gebrauch zu machen, I. um über die Zugehörigkeit der Sarkoide und des Lupus pernio zur Tuberkulose und 2. uber die Ursache der eventuellen Tuberkulinanergie zu einer Entscheidung zu kommen. Ich versuchte daher die von Pickert und Loewenstein ${ }^{5}$ ) angegebene Methode zum Nachweis der sog. Anticutin e heranzuzieben. Diese Autoren fanden, daß das Serum von Tuberkulösen, die gegen hohe Dosen Tuberkulin oder auch Bacillenemulsion unempfindlich sind, imstande ist, die Tuberkulinwirkung auf die Haut Tuberkulöser abzuschwächen bzw, aufzuheben. Diese im Serum enthaltenen Stoffe nannten sie Anticutine. Nach ihnen sind im normalen Serum diese spezifischen Stoffe, welche die s pezifische Tuberkulinwirkung a uf die Haut neutralisieren, nicht vorhanden. Bestätigt wurden diese Befunde von Hamburger

1) O. Gans, Dermatol. Zeitschr. 1921, S. 64.

2) Jadassohn, Arch. f. Dermatol, u. Syphilis, Orig. 113. 1912.

3) Jadassohn, Korrespondenzbl. f. Schweiz. Ärte 4\%. 1914.

4) Jadassohn, Korrespondenzbl. f. Schweiz. Ärzte 14. 1919.

5) Pickert und Loewenstein, Dtsch. med. Wochenschr. 1908, S. 2262. 
und Monti ${ }^{1}$, von v. Pirquet ${ }^{2}$, Escherich ${ }^{3}$, Citron ${ }^{4}$ ) u. a. Ich möchte hier auf die Kontroverse über die Anticutine nicht näher eingehen. Weder die von Zieler auf Versuchsfehler zurückgeführten Resultate Sorgos ${ }^{5}$ ) noch die Annahme von Kirsch und Szigeti ${ }^{6}$ ), daß das Neutralisationsphänomen nicht auf spezifischen Antikörpern vom Charakter echter Antitoxine beruht, noch die Versuche von Dünner und Horowitz ${ }^{7}$, daß die Aufhebung der Allergie auf Kolloidwirkung zurückzuführen sei, können die Beobachtung aus der Welt schaffen, daB einzelne Tuberkulöse ohne, viele andere nach Vorbehandlung mit Tuberkulin ein die Tuberkulinwirkung abschwächendes Serum liefern. Die Sera, der anderen Tuberkulösen haben diese Wirkung nicht. Von dem Serum Nichttuberkulöser haben zwar Dünner und Horowitz solche Wirkungen; gesehen ich habe das bei meinen Kontrollversuchen (allerdings nur bei 8 Normalseris) nicht konstatieren können. Es könnte sehr wohl diese tuberkulin-paralysierende Wirkung des Serums auf einer an sich nicht spezifischen Substanz beruhen. Aber - ähnlich wie bei der Wassermannschen Reaktion - müßte dann diese Substanz unter bestimmten Umständen eine Anreicherung erfahren, die eben für diese Gruppe der Tuberkulösen (bzw. nach der Tuberkulinbehandlung) das Manifestwerden des Pickert - Loewensteinschen Phänomens bedingt. Wie dem auch sei, ich habe es jedenfalls (längere Zeit vor dem Erscheinen der Arbeit von Dünner und Horowitz) für notwendig gehalten, das Serum der Sarkoid- und Lupus-pernio-Kranken nach der Pickert. Loewensteinschen Methode zu untersuchen.

Methode von Pickert und Loewenstein: Entnahme ron Blut aus der Armvene durch Punktion. Nach 6 Stunden Abgießen des Serums. Dieses wird mit steigenden Mengen A. T. versetzt, so da $B$. T.-Serummischungen von $5 \%$, $20 \%$ und $50 \%$ entstehen. Die Mischung kommt für $1^{1 / 2}-2$ Stunden in den Brutschrank und wird am besten nach 24 Stunden nach der Pix quetschen Methode verwendet. Als Kontrolle wird ein Normalserum, d. h. ein Serum von klinisch nicht tuberkulösen, gegen Tuberkulin anergischen Patienten, in der gleichen Weise behandelt und verimpft. Nach seinen späteren Angaben hat Lo ewe nstein ${ }^{8}$ ) die Methode derart abgeändert, daß er A. T.-Serummischungen von $1 \%, 2 \%$ und $5 \%$ verwendet, die 2 Stunden in den Brutschrank kommen, dann im Eisschrank aufbewabrt und nach 24 Stunden verimplt werden.

Ich wandte die Methode in der gleichen Weise an; nur daß ich statt des Serums von sicher tuberkulösen Individuen, die Immunität gegenüber

1) Hamburger und Monti, Brauers Beiträge XVI (Antikörper).

2) v. Pirquet, Handbuch der Technik der Immunitätsforschung 1910.

3) Escherich, Wien. klin. Woohensebr. 1910, S. 723.

4) Citron, Berl. klin. Wochenschr. 1909, S. 2288.

5) Sorgo, Wien. klin. Wochenschr. 1913, S. 1837.

6) Kirsch und Szigeti, Beitr. zur Tuberkulose 45, 325. 1920.

7) Dünner und Horowitz, Berl. klin. Wochensohr. 1921, S. 665.

8) Loewenstein im Handbuch von Kolle-Wassermann 5, 609. 
hohen Dosen von Tuberkulin zeigen, Sera von Lupus-pernio- und SarkoidKranken nahm, die sämtlich negative Pirquet- und IntradermoReaktionen (mit A. T. 1:5000 und $1: 1000$ ) aufwiesen. Beim ersten Versuch verwandte ich A. T.-Serummischungen von $5 \%, 20 \%$ und $50 \%$, später von $1 / 2 \%, 1 \%$ und $5 \%$, bzw. $1 \%, 5 \%$ und $10 \%$.

Ich verfüge über 5 Fälle, davon 2 Fälle von Lu pus pernio (der eine wurde mir freundlicherweise von Herm Primärarzt Dr. K uznitzky Allerheiligenhospital-Breslau - zur Verfügung gestellt) und 3 Fälle von Sarkoid Boeck. Ich bin mir bewußt, daß dieses Material sehr klein ist, aber alle Versuche, es zu vermehren, sind fehlgeschlagen. Alte Patienten sind trotz mehrfacher Aufforderung nicht erschienen, neue Fälle kommen in überaus großen Zwisehenräumen sehr spärlich. Die Versuche von anderen Stellen, so auch aus der Berliner Klinik, mehx Material zu bekommen, sind bisher erfolglos geblieben. So habe ich mich entschlossen, meine Ergebnisse zu veröffentlichen, damit sie an möglichst vielen Fällen nachgeprüft werden können. Es ist zu hoffen, daß durch die Untersuchung einer großen Zahl von Fällen mit dieser Methode definitiv festgelegt werden wird, ob sie zur Entscheidung der obigen Fragen brauchbar ist, und ob meine vorläufigen Resultate sich bestätigen werden.

\section{Protokolle.}

Von einer ausführlichen Angabe der Befunde, Reaktionsgröße, Durchmesser in Millimetern gemessen und Stärke der Infiltration nach Pirquet. muß aus bekannten Gründen abgesehen werden. Die Resultate wurden nach 24, 48, 72 und 96 Stunden abgelesen. Als Testobjekte wurden Lupuskranke verwandt. Impfstelle: Unter- und Oberarme, Beuge- und Streckseiten. Kontrollen: Normalserum (siehe oben) in entsprechender Mischung mit A.T., Normalserum allein, Pernio- und Sarkoidserum allein. Daß in den einzelnen Versuchsreihen immer eine Anzahl von Geimpften eine negative Impfreaktion mit allen Mischungen zeigte, ist erklärlich, wenn man die geringen Tuberkulinkonzentrationen in Betracht zieht, die angewandt wurden. Loewenstein selbst hat auf diese Erscheinung aufmerksam gemacht und darauf hingewiesen, daß man deshalb die Zahl der Fälle, die geimpft werden, nicht zu klein nehmen soll (Kolle-Wassermann, Bd.V, S. 609).

Ia) Lupus pernio. (Tsch.) Serum verimpft anf 13 Lupuskranke. Die Wirkung des Serums

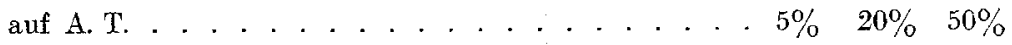

war absehwächend . . . . . . . . . . . . . 4 4 7 6 mal

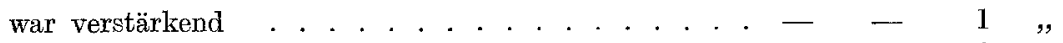

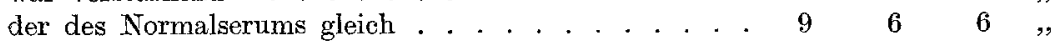

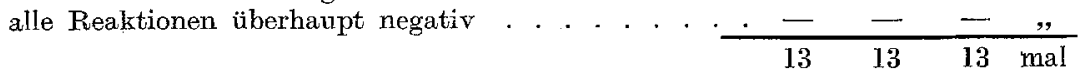


Es muß hier auffallen, daß bei den höheren Tuberkulinkonzentrationen öfter ein Unterschied im Grade der Reaktion festzustellen war als bei der $5 \%$ A.-T.-Serummischung. Dies wird in der Hauptsache dadurch zu erklären sein, daß Differenzen unter $2 \mathrm{~mm}$ bei der Messung des Durchmessers in allen Fällen nicht mehr berücksichtigt wurden und dies natürlich bei der an sich viel kleineren Reaktionsgröße der 5\%Mischung öfters zu einer Gleichsetzung der Resultate führen mußte als bei den stärkeren Reaktionen der wesentlich höheren A. T.-Konzentrationen. Da aber im ganzen oft ein deutlicher Unterschied nicht festzustellen war, wurden in allen folgenden Untersuchungen A. T:Serummischungen mit einem Gehalt an A. T. von $1 / 2$, I und $5 \%$, bzw. $10 \%$ angewandt.

Ib) Lupus pernio. (Tsch.) "Serum verimpft auf 13 Lapuskranke. Die Wirkung des Serums auf

A. T.

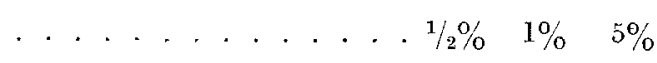
war abschwächend . . . . . . . . . . . . 7 7 6 6 7 mal war verstärkend . . . . . . . . . . . . . . . . . 1 l 1 l 1 "

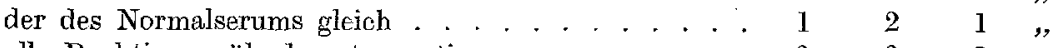

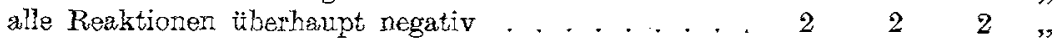
an den Impfstellen mit A. T.-Pernioserum ein anämischer

Hof, dabei A. T.-Normalserumreaktion negativ . $\begin{array}{rrrr}2 & 2 & 2 & 2 \\ 13 & 13 & 13 & \text { mal }\end{array}$

In diesem Falle wurden positive Reaktionen überhaupt erzielt mit $1 / 2 \%$ A. T. + Pernioserum: $3,{ }_{1}^{1} / 2 \%$ A. T. + Normalserum: $7,1 \%$ A. T. + Pernioserum: 4, 1\% A. T. + Normalserum: 8, 5\% A. T. + Pernioserum: 7, 5\% A. T. + Normalserum: 9. An den A. T. + PernioserumImpfstellen entstand als einzige Reaktion ein anämischer Hof in 4 Fällen, dabei war die Reaktion A.T. + Normalserum 2 mal negativ, 2 mal deutlich positiv.

II. Lupus pernio. (J.) Serum verimpft auf 16 Lupuskranke. Die Wirkung des Serums auf

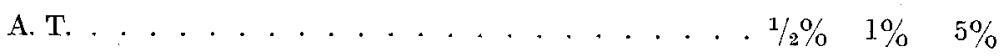
war abschwächend . . . . . . . . . . . . . . $11 \quad 12$ 11 mal

war verstärkend . . . . . . . . . . . . . - - - "

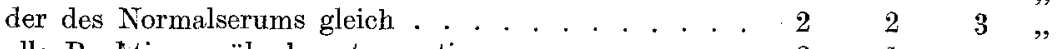

alle Reaktionen überhaupt negativ ......... 2 . 1 1 ", az den Impfstellen mit A. T.-Perinoserum ein anämischer

Hof, dabei A.-T.-Normalserumreakt. negativ . . . \begin{tabular}{rrrrr}
1 & 1 & 1 & \\
\hline 16 & 16 & 16 & $\mathrm{mal}$
\end{tabular}

Positive Reaktionen überhaupt mit $1 / 2 \%$ A. T. + Pernioserum: 4 , $1 / 2 \%$ A. T. + Normalserum: 12, 1\% A. T. + Pernioserum: 7, 1\% A. T. + Normalserum: 13,5\% A. T. + Pernioserum: 12, 5\% A. T. + Normal. serum: 14. Anämischer Hof war bei A. T. + Pernioserum festzustellen 
in 6 Fällen, dabei war die entsprechende Reaktion A. T. + Normalserum 1 mal negativ, 5 mal positiv, jedoch waren unter diesen 5 Fällen 3 mit ebenfalls anämischem Hof am 1.-2. Tag.

IIIa) Sarkoid Boeck. (J.) Serum verimpft auf 12 Lupuskranke. Die Wirkung des Serums auf

A. T.

\begin{tabular}{ccccc}
$.1 / 2 \%$ & $1 \%$ & $5 \%$ & \\
. & - & - & - & mal \\
. & - & - & 9 & $\#$ \\
. & 2 & 2 & 1 & $"$ \\
\hline 12 & 12 & 12 & mal
\end{tabular}

Positive Reaktionen überhaupt mit $1 / 2 \%$ A. T. + Sarkoidserum: 10, $1 / 2 \%$ A. T. + Normalserum: 3, 1\% A. T. + Sarkoidserum: 10, 1\% A. T. + Normalserum: 3, 5\% A. T. + Sarkoidserum: 11, 5\% A. T. + Normalserum: 6 .

IIIb) Sarkoid Boeck. (J.) Serum verimpft auf 12 Lupuskranke. Die Wirkung des Serums auf

A. T. . . . . . . . . . . . . ${ }^{1 / 2} \% \quad 1 \% \quad 5 \%$

war abschwächend . . . . . . . . . . - - $\quad$ mal

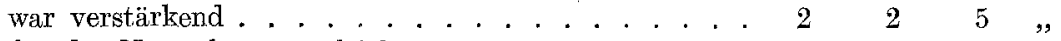

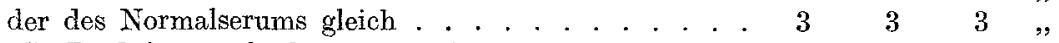

alle Reaktionen überhaupt negativ $\ldots \ldots . . .7$\begin{tabular}{rrrrr}
7 & 7 & 7 & 4 & " \\
\hline 12 & 12 & 12 & mal
\end{tabular}

Positive Reaktionen überhaupt mit $1 / 2 \%$ A. T. + Sarkoidserum: 4, $1 / 2 \%$ A. T. + Normalserum: $2,1 \%$ A. T. + Sarkoidserum: 4, $1 \%$ A. T. + Normalserum: 4, 5\% A. T. + Sarkoidserum: 7, 5\% A. T. + Normalserum: 6. Bei einem Lupuskranken trat an allen Impfstellen als einzige Reaktion ein anämischer Hof auf, ein Unterschied zwischen Sarkoidund Normalserum war nicht festzustellen.

IV. Sarkoid Boeck. (M.) Serum verimpft auf 9 Lupuskranke. Die Wirkung des Serums auf

A. T. . . . . . . . . . . . . ${ }^{1 / 2} \% \quad 1 \% \quad 5 \%$

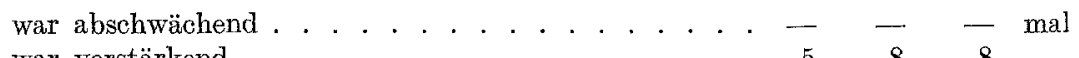

war verstärkend . . . . . . . . . . . . . . . . $55^{5} 88^{8}$

der des Normalserums gleich . . . . . . . . . . . . - - - - -

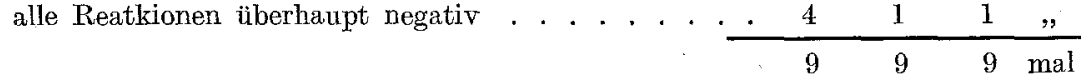

Positive Reaktionen überhaupt mit $1 / 2 \%$ A. T. + Sarkoidserum: 5 , $1 / 2 \%$ A. T. + Normalserum: $2,1 \%$ A. T. + Sarkoidserum: $8,1 \%$ A. T. + Normalserum: $3,5 \%$ A. T. + Sarkoidserum: $8,5 \%$ A. T. + Normalserum: 5.

Va) Sarkoid Boeck. (Sch.) Serum verimpft auf 4 Lupuskranke. Die Wirkung des Serums auf 
A. T.

\begin{tabular}{rrrrr}
. & $1 / 2 \%$ & $1 \%$ & $5 \%$ & \\
. & - & - & - & $\mathrm{mal}$ \\
. & - & 2 & 4 & $"$ \\
. & - & - & - & $"$ \\
\hline 4 & 4 & - & $"$ \\
\hline & 4 & 4 & $\mathrm{mal}$
\end{tabular}

Positive Reaktionen überhaupt mit $1 / 2 \%$ A. T. + Sarkoidserum: 0 , $1 / 2 \%$ A. T. + Normaiserum: $0,1 \%$ A. T. + Sarkoidserum: $2,1 \%$ A. T. + Normalserum: $0,5 \%$ A. T. + Sarkoidserum: $4,5 \%$ A. T. + Normalserum: 3 .

Vb) Sarkoid Boeck. (Sch.) Serum verimpft auf 5 Lupuskranke. Die Wirkung des Serums auf

A. T. . . . . . . . . . . . . $1 \% \quad 5 \% \quad 10 \%$

war abschwächend . . . . . . . . . . . . - - - mal

war verstärkend. . . . . . . . . . . $4.4 \%$

der des Normalserums gleich . . . . . . . . . . - - - "

alle Reaktionen überhaupt negativ ...... . $\begin{array}{lllll}5 & 5 & 1 & 1 & \text { " }\end{array}$

Positive Reaktionen überhaupt nit 1\% A. T. + Sarkoidserum: 0 , $1 \%$ A. T. + Normalserum: 0, 5\% A. T. + Sarkoidserum: 4, 5\% A. T. + Normalserum: $1,10 \%$ A.'T. + Sarkoidserum: 4, 10\% A.T. + Normalserum: 4 .

Die Kontrollimpfungen mit reinem Normal-, Pernio- und Sarkoidserum waren in allen Versuchsreihen negativ.

Weitere Angaben über den verzögerten Eintritt der Reaktion, über die Stärke der abschwächenden bzw. verstärkenden Wirkung der Sera bei den verschiedenen Kranken usw. haben zur Zeit bei dem geringen zur Verfügung stehenden Material kaum einen Wert. Erwähnen möchte ich auch noch die in mehreren Protokollen angeführten anämischen Reaktionen. „Es waren weiße Zonen von verschiedener Größe" (4 bis $6 \mathrm{~mm}$ ) ohne Infiltration - nur das Impfkrüstchen - nach 24 Stunden, und selbst auch nach 72 Stunden, zu konstatieren. Daß sie nicht bloß auf das A. T.-Pernioserum zurückzuführen sind, beweist der Fall IIIb, in dem diese eigenartige Reaktion bei einem Lupuspatienten auch bei A. T.-Sarkoid- und A.T.-Normalserum gleichzeitig auftrat. Auch dieses Phänomen bedarf eingehenden Studiums.

Nach den vorstehenden Ergebnissen scheint das Seru m von Lup us. pernio- und Sarkoid-Kranken Stoffe zu enthalten, die die Wirkung des Tuberkulins a uf die Haut Tuberkulöser deutlich beeinflussen. Die Einwirkung war nach dem vorliegenden Material derart, daß das Serum von 2 Lupus-pernio-Kranken die Tuberkulinwirkung abschwächte, das Serum der 3 Sarkoid-Boeck-Kranken diese Wirkang verstärkte. 
324 H. Martenstein: Wirkung des Serums ron Sarkoid-Boeck-Kranken nsw.

Diese Resultate sind sehr auffallend. Bei zwei Krankheiten, die beide der tuberkulösen Ätiologie zum mindesten sehr verdächtig sind und sich beide durch ihre relative oder absolute Unempfindlichkeit gegen Tuberkulin auszeichnen, scheint das Serum Stoffe zu enthalten, welche zum Tuberkulin eine Beziehung haben, die einen aber heben die Tuberkulinwirkung auf (Anticutine?), die anderen steigern sie (Procutine?). Auch das wäre theoretisch noch allenfalls zu erklären, denn die beiden Krankheiten sind zwar sehr ähnlich, aber nicht identisch, und auch das Stadium der Erkrankung könnte eine Rolle spielen. Man könnte auch daran denken, daß die Differenzen auf der Verschiedenheit der Stadien beruhen und daß ich zufällig beim Pernio immer das eine, beim Sarkoid das andere gefunden habe. Ehe wir aber auf solche theoretische Erwägungen eingehen, wie sie auch in der letzten Publikation von Altmann und Gans angestellt werden, muß das Material, auf das sie sich stützen könnten, wesentlich größer sein. 